\title{
Index-Based Study of Future Precipitation Changes over Subansiri River Catchment under Changing Climate
}

\author{
G. Shivam, M. K. Goyal", and A. K. Sarma \\ Department of Civil Engineering, Indian Institute of Technology Guwahati, Assam-781039, India
}

Received 6 May 2016; revised 9 January 2017; accepted 19 March 2017; published online 5 October 2017

\begin{abstract}
This study focuses on the long-term (2011 2100) changes in precipitation indices under different climate change scenarios in Subansiri river basin, a tributary of Brahmaputra River in Northeast India. The fifth phase coupled model intercomparison project (CMIP5) data for different representative concentration pathways (RCPs) scenarios as suggested by Intergovernmental Panel on Climate Change (IPCC) is used for the study. Statistical downscaling model (SDSM) is used to downscale the precipitation. Three global climate model (GCM) datasets from earth system model and geophysical fluid dynamics laboratory (namely ESM2G, ESM2M, and GFDL-CM3) with four RCP scenarios (namely RCP2.6, RCP4.5, RCP6.0, and RCP8.5) were used for generating daily precipitation time series for a time period of 2011 to 2100. Precipitation based indices were computed on a multi-decadal time scale to detect the changes in precipitation pattern and its distribution. Total five precipitation stations were selected for downscaling and precipitation indices analysis. The non-parametric Mann-Kendall test method was used for the trend analysis of the precipitation indices. Indices based analysis of the precipitation shows an increase in the intensity of precipitation whereas a decrease in number of precipitation days on the lower part of the basin. The increase in number of rainy days followed by a decrease in intensity in the upper station was observed. Long-term (2011 2100) future projection of precipitation for annual precipitation shows statistically significant increase of minimum $1.8 \%$ at station 1 (for RCP2.6) to maximum 11\% in station 3 (for RCP8.5) as compared to observed period annual precipitation.
\end{abstract}

Keywords: downscaling, CMIP5, RCP, precipitation indices, trend analysis, Subansiri river

\section{Introduction}

Management of water resources under the threat of changing climate is a big challenge for policymakers and researchers (Vano et al., 2010; Valipour 2012; Sarma et al., 2013). Several climate change studies reported that global warming will increase the water holding capacity of the atmosphere which may cause an increase in the precipitation intensity (Allen and Ingram 2002; Berg et al., 2009). IPCC in its fifth assessment report (AR5) reported that the occurrence of extreme precipitation events will be more frequent in many regions and rise in temperature in the 21 st century for all the greenhouse gas emission scenario (IPCC, 2014). Alteration in climatic variables will affect various sectors e.g. agriculture, ecosystem, water quality and water resources etc. Swain and Thomas (2010) carried out a study to evaluate the climate change impact on agricultural production using multiple GCMs for Eastern India and reported the reduction in future agricultural production, apart from agricultural losses climate

\footnotetext{
* Corresponding author. Tel.: +91-361-2583328; fax: +91-361-2582440.

E-mail address: vipmkgoyal@gmail.com (M. K. Goyal).
}

ISSN: 1726-2135 print/1684-8799 online

(C) 2019 ISEIS All rights reserved. doi: 10.3808/jei.201700376 change will also affect the water quality of different waterbodies (Xia et al., 2014). Change in temperature and precipitation will have direct impact on calculation of hydro-climatological parameters such as evapotranspiration (Valipour and Eslamian 2014; Valipour 2014; Goyal and Khan 2016; Goyal and Sharma 2016; ) which in turn will affect the basin response such as streamflow (Valipour et al., 2013; Valipour 20 15), sediment discharge etc.

GCMs are the useful tool for the climate change studies to predict the future probable change in the atmospheric components under the different greenhouse gas emission scenarios (Ghosh and Mujumdar 2008; Moss et al., 2010). GCMs include physical factors of the area while generating the future scenarios for different carbon concentration levels (Grotch and MacCracken 1991; Prudhomme et al., 2003) though the problem associated with these models is the coarse resolution, which makes it unfit for use at local scale impact studies (Goyal and Ojha, 2012). Emission scenarios considered for this study are relevant to the IPCC AR5 based CMIP5 datasets which are the advanced phase of coupled model inter-comparison projects (CMIP). CMIP5 datasets are simulated on the basis of representative concentration pathway (RCP) scenarios which implicate the radiative forcing; RCPs unlike special report on emission scenario (SRES) datasets include policy intervention along with technological, population and 
societal development while explaining the emission scenarios (Taylor et al., 2012). RCPs are the scenarios which assume that policy intervention and precautionary measures will be taken into consideration to keep the emission to a certain level.

In climate change studies local scale factors such as topography, water bodies, land use land cover etc. play important role in occurrence and distribution of the various atmospheric variables (Ghosh and Mujumdar 2008; Mondal and Mujumdar 2012). Downscaling of large scale GCM variables to bring down to the local scale helps in understanding the impact of local factors affecting the atmospheric processes (Anandhi et al., 2008). There are several methods for downscaling e.g. dynamic downscaling, statistical downscaling and weather generators but statistical downscaling is popular technique because of its computational efficiency, flexibility and capability to get station scale information from coarse GCM (Wilby et al., 2002). Rahmani and Zarghami (2015) applied downscaling approach to assess the change in temperature and precipitation over Northwestern Iran and found a decrease in precipitation and increase in warming for the various climate change scenarios.

Expert team on climate change detection and monitoring (ETCCDI) has decided certain climate extreme indices; these climate indices are included in the fourth assessment report of IPCC (IPCC 2007). Precipitation indices are the indicator of the occurrence and distributions of the precipitation during a period of time and their trend analysis can be very helpful in identifying the changing pattern of precipitation (Katz and Brown, 1992; Valipour 2016). Pingale et al. (2014) carried out a study on precipitation trends over 33 stations of Rajasthan state of India for the period of $1971 \sim 2005$ and reported a decrease in precipitation by $6 \sim 8 \mathrm{~mm} /$ year whereas an increase in temperature was recorded. Duhan and Pandey (2013) in their study over 45 districts of Madhya Pradesh state of India for trend analysis of precipitation with a dataset from $1901 \sim 1978$ found that trend of precipitation in the region decreasing with maximum recorded magnitude of $12 \%$ to minimum with $8.52 \%$.

Recent studies on climate change and trend analysis over Northeast India also indicate vulnerability of the region to climate change impacts. Jhajharia et al. (2012) applied MannKendall test to detect the trend in evapotranspiration in the northeast India region and claimed decrease in evapotranspiration over the region. Goyal (2014) studied the trend of precipitation in northeast India and found notably significant seasonal variation of the precipitation at various stations for agricultural and water management point of view. Deka et al. (2013) in their study for trend analysis of precipitation over Brahmaputra river and Barak river basin and reported a decreasing trend in annual and monsoon precipitation over both the basins. Jain et al. (2013) analyzed the trend in temperature and precipitation over the northeast India using the 1871 2008 datasets and reported seasonal changes in precipitation and rise in temperature of the region. Since the northeast part of India is high precipitation receiving region, short duration high-intensity precipitation causes destruction in the region and also it intensifies the necessity of the water management for the region as rainy season causes massive flood situation whereas in lean period water scarcity arises in some parts (Das et al., 2009). Recent studies reveal an increase in the occurrence of the extreme events in the region, such as NorthLakhimpur district has faced several frequent flash floods while districts like Nagaon and Carbi Anglong are facing a water scarcity situation (Das et al., 2009). The main objective of the study is to quantify the impact of climate change associated with precipitation in Subansiri river basin using precipitation indices approach using recently introduced CMIP5/RCP datasets.

\section{Study Area and Data}

Subansiri river basin, selected for the study is a tributary of Brahmaputra River in the Northeastern part of India. It originates from Tibet plateau and enters in India through the state of Arunachal Pradesh and after traveling a distance of $334 \mathrm{~km}$ it meets Brahmaputra River near Gerukamukh in the Assam state. River drains about $35771 \mathrm{~km}^{2}$. The geographical extent of the river basin lies between latitude $26^{\circ} 54^{\prime} 14.72^{\prime \prime} \mathrm{N}$ to $28^{\circ} 55^{\prime} 24.79^{\prime \prime} \mathrm{N}$ and longitude $91^{\circ} 33^{\prime} 09.83^{\prime \prime} \mathrm{E}$ to $95^{\circ} 04^{\prime} 38$. 44"'E (Figure 1). This river covers part of Lower Subansiri district in the state of Arunachal Pradesh and some part of Dhemaji and North Lakhimpur district of Assam.

India Meteorological Department (IMD) gridded precipitation data of $0.5^{\circ}$ latitude $\times 0.5^{\circ}$ longitudes is used as observed data (for station 2, station 3 and station 4). IMD grided data are the products of interpolation of high-quality gauge station data from more than 1800 stations (Rajeevan et al., 2006). Apart from these gridded data one precipitation gauge station data (for station 5) is also available for study. Since there is no IMD gauge stations and IMD gridded datasets are available for the upper region, APHRODITE gridded $\left(0.5^{\circ} \times\right.$ $0.5^{\circ}$ ) precipitation dataset was used as observed data. Asian Precipitation Highly Resolved Observational Data Integration Towards Evaluation of the Water Resources (APHRODITE) is

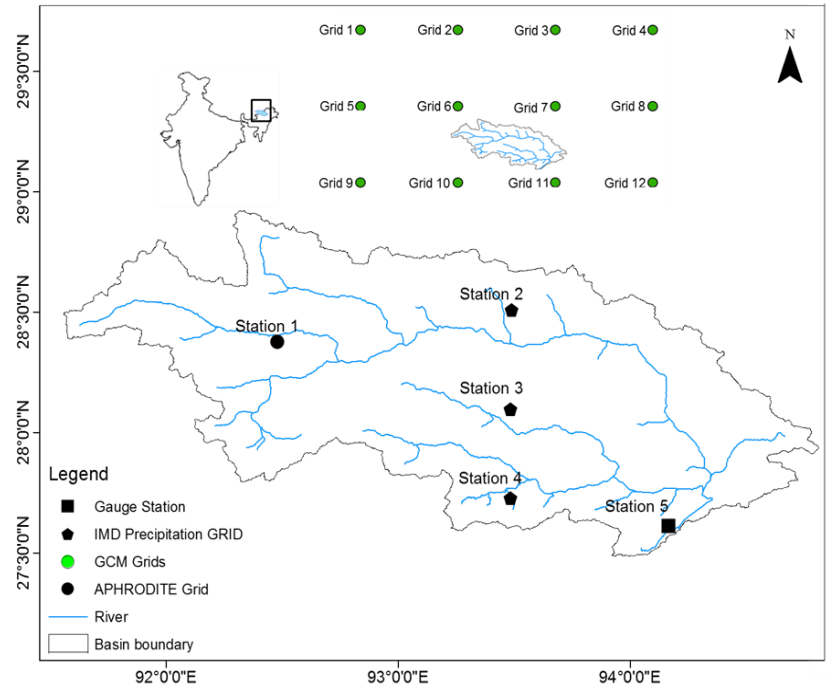

Figure 1. Subansiri River Basin and station details. 
the high resolution $\left(0.25^{\circ} \times 0.25^{\circ}\right.$ and $\left.0.5^{\circ} \times 0.5^{\circ}\right)$ daily rainfall data sets developed for the Asian region which is based on the data collected at more than 5,000 stations (Yatagai et al., 2012). CMIP5 GCM dataset variable was downloaded from Geophysical fluid dynamics laboratory (GFDL). Three GCMs namely ESM2G, ESM2M and GFDL-CM3 (downloaded from website: https://esgf-data.dkrz.de/search/cmip5-dkrz/) with their respective RCP scenarios daily datasets i.e. RCP2.6, RCP4.5, RCP6.0 and RCP8.5 for the period of 2011 to 2100 were utilized in this study for downscaling of the future precipitation. Since the gauge precipitation dataset is available from 1980 to 2000, to keep the uniformity in data period for all the stations, we selected this period $(1980 \sim 2000)$ data for calibration and validation for all the selected stations. National Center for Environmental Prediction (NCEP) datasets were used for model preparation, calibration and validation purposes. Since GCM grid resolution $\left(2^{\circ} \times 2.5^{\circ}\right)$ and NCEP data sets grid resolution $\left(2.5^{\circ} \times 2.5^{\circ}\right.$ lat $\times$ lon $)$ are not same, before downscaling GCM predictors were interpolated to NCEP grid scale using inverse distance weighted average method (IDWA) (Willmott et al., 1985).

\section{Methodology}

\subsection{Downscaling}

There are mainly two downscaling methods which are used in climate change studies i.e. statistical downscaling and dynamic downscaling. The statistical downscaling method establishes a relation between GCM variables and historical time series of observed variable (predictands), this method is more popular because of its ease of calculation and fewer resources requirement whereas dynamic downscaling is complicated and requires high computational facility (Wilby and Wigley 2000). SDSM is widely accepted model for the statistical downscaling, several previous studies have used this model (Khan et al., 2006; Chu et al., 2008; Hashmi et al., 2011; Mahmood and Babel 2013; Meenu et al., 2013; Duhan and Pandey 2014; Shivam et al., 2016). In this study statistical downscaling model (SDSM) is used for the downscaling, SDSM is a statistical tool which utilizes linear regression transfer function between observed datasets (predictands) and the NCEP variables (predictors) and works as a stochastic weather generator for future projection of the predictand variable. SDSM establishes linear regression relation between predictand and large-scale variables. There are three methods available for making the regression model i.e. monthly, annual and seasonal basis. In monthly model different regression equations are drawn for each month whereas in annual model single regression equation is established for all the months. The model uses conditional sub-model for generating the precipitation events on the basis of dry and wet spells (Wilby et. al., 2002). Optimization of the parameter is performed using ordinary least square method or simplex method. In this study monthly model was prepared for downscaling, regression relation was established for each month separately and ordinary least square method was used for parameter optimization. There are four main sections in SDSM model i.e. sc- reen variables, calibrate the model, weather generator and scenario generator. Screen variables section performs several statistical checks for selection of suitable variables for model preparation, calibrate model section establishes regression equation between predictand and GCM/NCEP variables by optimizing the parameters of regression equations, and weather generator generates the future time series for different climate change scenarios.

\subsection{Potential Predictor Selection}

Predictor selection is the most important step in the downscaling process. For selecting the potential predictors, initially correlation check between observed precipitation of selected stations and NCEP variables was performed. In the selection of predictors, it is to be noted that the correlation between observed variables (predictands) and NCEP variables (predictors) should be maximum and correlation amongst the predictors should be minimum (Wilby and Wigley, 2000). After checking the correlation, 17 most relevant predictors were selected for choosing the final predictors for model preparation. Further, partial correlations amongst the predictors were checked, this methodology of selecting the predictors, was adopted from Mahmood and Babel (2013). Finally, the predictors such as surface specific humidity (huss), precipitation flux (pr), convective precipitation flux (prc), surface relative humidity (rhs), surface daily minimum humidity (rhsmin), surface daily maximum humidity (rhsmax) and surface down-welling longwave radiation (rlds), temperature at surface (tas) were selected for preparing the model.

For preparing the downscaling model, dataset from 1980 $\sim 1995$ is used for calibration whereas $1995 \sim 2000$ dataset is used for validation. Nearest four grid points of the selected three GCMs were first interpolated to NCEP grids and then standardized to reduce systemic biases in mean and variance of the GCM. NCEP variables were normalized using the mean and standard deviation of the NCEP data series from 1980 2000 using the following formula:

$x_{\text {normalized }}=\frac{x-\bar{x}}{\sigma}$

where ' $x$ ' is the data point in series, $\bar{x}$ is mean of the time series and $\sigma$ is standard deviation.

For evaluating the model performance, several performance metrics were calculated for the prepared downscaling model over calibration and validation period.

1) Coefficient of determination $\left(R^{2}\right)$ :

$$
R^{2}=\left(\frac{\sum_{i=1}^{n}\left(\mathrm{O}_{i}-\bar{O}\right)\left(\mathrm{P}_{i}-\bar{P}\right)}{\sqrt{\sum_{i=1}^{n}\left(\mathrm{O}_{i}-\bar{O}\right)^{2}} \sqrt{\sum_{i=1}^{n}\left(\mathrm{P}_{i}-\bar{P}\right)^{2}}}\right)^{2}
$$


2) Nash-Sutcliffe Efficiency (NSE):

$$
N S E=1-\frac{\sum_{i=1}^{n}\left(O_{i}-P_{i}\right)^{2}}{\sum_{i=1}^{n}\left(O_{i}-\bar{O}_{i}\right)^{2}}
$$

3) Root Mean Square Error (RMSE):

$$
R M S E=\sqrt{\frac{\sum_{i=1}^{n}\left(\mathrm{O}_{i}-P_{i}\right)^{2}}{n}}
$$

where $O_{i}$ and $P_{i}$ are the observed and model generated precipitation dataset respectively, and $\bar{O}$ and $\bar{P}$ are the mean of observed and model generated precipitation data series respectively. Further bias correction of the future generated precipitation data series was performed using Equation 5, bias correction of the downscaled data is necessary for the accurate impact assessment from the downscaled variables (Dettinger et al., 2004). For bias correction of the downscaled data following method was applied (Mahmood and Babel, 2013):

$$
P_{d}=P_{\text {downscaled }} X\left(\overline{\frac{P_{o b s}}{P_{\text {cont }}}}\right)
$$

where $P_{d}$ is bias corrected precipitation series, $\overline{P_{o b s}}$ is mean of the observed precipitation and $\overline{P_{\text {cont }}}$ is mean of downscaleed precipitation data for the calibration period.

\subsection{Precipitation Indices}

Precipitation indices as decided by ETCCDI are characterized by the duration and intensity of the precipitation (Alexander et al., 2006). Precipitation indices were calculated following the ETCCDI norms and nine indices of precipitation namely consecutive dry days (CDD), consecutive wet days (CWD), annual precipitation (PRCPTOT), number of rainy days $(\mathrm{R} 1 \mathrm{~mm})$, heavy precipitation days $(\mathrm{R} 10 \mathrm{~mm})$, very heavy precipitation days (R20mm) very wet days (R95p), extremely wet days (R99p) and simple daily intensity index (SDII) was computed. Indices like CDD, CWD, R1mm give an idea of the distribution of the precipitation throughout the year whereas indices R95p, R99p and SDII indicate about the intensity of the precipitation (Donat et al., 2013; Huang et al., 2014). Number of days having precipitation amount more than $1 \mathrm{~mm}$ is considered rainy days, previous studies selected this value as a threshold for calculating the rainy days (Sillmann et al., 2013).

\subsection{Trend Analysis}

Mann-Kendall test (Mann, 1975; Kendall, 1975) was ap- plied to detect the changes in precipitation indices and Sen' slope method (Sen, 1968) was used for the calculation of the magnitude of change in trend. Mann-Kendall z-statistics calculated for test of significance of trend at $95 \%$ confidence level, the value of $\mathrm{z}$-statistics greater than +1.96 indicates a significant positive trend and a value less than -1.96 tends to significant decreasing trend. Auto-correlation amongst the datasets reduces the efficiency of Mann-Kendall test in detecting the trend, in such cases pre-whitening of datasets is required to get the accurate results (Burn and Elnur, 2002). In this study, before testing the trend of precipitation indices, autocorrelations were checked for each indices datasets and it was found that there is no statistically significant auto-correlation existing in datasets at $95 \%$ confidence level.

\section{Results and Discussion}

\subsection{Downscaling Results}

After selecting the predictors, downscaling model was prepared using linear regression with conditional sub-model; conditional sub-model implicates separate parameterization for dry days and wet days from the series of precipitation (Wilby et al., 2002). RMSE, $R^{2}$, and NSE value for the calibration and validation period are shown in Table 1 and graph plot of observed and model generated precipitation is shown in Figure 2. As shown in Table $1, R^{2}$ varies from 0.76 to 0.81 in calibration period whereas in the validation period, it ranges from 0.78 to 0.88 for different stations. NSE found to be ranging from 0.78 to 0.88 during calibration and 0.74 to 0.83 in validation.

Calibrated downscaling model was further used to generate the precipitation for baseline scenario $(1980 \sim 2000)$ using historical run of the three GCM models. These historical GCM runs simulate the atmospheric variables on the basis of observed carbon concentration (Moss et al., 2010; Taylor et al., 2012). Figure 3 shows a boxplot of the monthly observed precipitation, the monthly model generated precipitation data series and monthly precipitation series generated from historical run of GCM data. Station-wise results of the precipitation downscaling model on monthly basis show good agreement with the observed precipitation but a comparison of the annual precipitation of observed data and model generated data shows that model overestimates the annual precipitation whereas the historical run GCM precipitation data shows an almost similar pattern to that of the model generated data.

Figure 4 represents the comparison of observed annual precipitation and precipitation series of RCP scenarios for $2011 \sim 2100$. Figure 4(a) shows changes in precipitation over station 1, results show increase in annual precipitation for all the RCP scenarios with variation in magnitude with GCM. Average of all three GCM shows an increase of $4.39 \%$ for RCP2.6, 5.17, 5.88 and $8.86 \%$ respectively for RCP4.5, RCP6.0, and RCP8.5. Figure 4(b) shows the precipitation for station 2 and average of three GCM indicates an increase of $3.21,7.65,9.07$ and $11.83 \%$ respectively for RCP2.6, RCP4.5, RCP6.0, and RCP8.5. Similarly, Figure 4(c), 4(d) and 4(e) re- 
Table 1. Calibration and Validation Results of Precipitation Downscaling Model for all Stations

\begin{tabular}{lllllllllll}
\hline & SB1 & & SB2 & & SB3 & & SB4 & SB5 & \\
\hline & Calibration & Validation & Calibration & Validation & Calibration & Validation & Calibration & Validation & Calibration & Validation \\
RMSE & 35.50 & 36.54 & 31.10 & 37.21 & 29.54 & 34.43 & 31.23 & 35.84 & 27.13 & 31.97 \\
CC & 0.81 & 0.79 & 0.83 & 0.79 & 0.85 & 0.81 & 0.83 & 0.80 & 0.76 & 0.74 \\
NSE & 0.80 & 0.78 & 0.82 & 0.78 & 0.88 & 0.83 & 0.81 & 0.79 & 0.78 & 0.74 \\
\hline
\end{tabular}

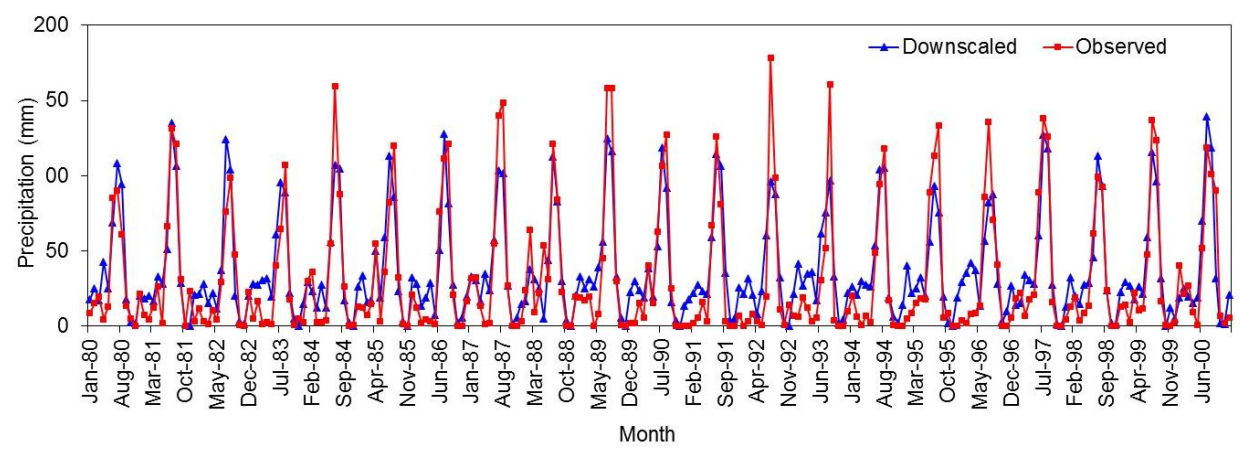

Figure 2. Calibration (1980-1995) and validation (1996-2000) result of the precipitation downscaling model for Subansiri river basin.
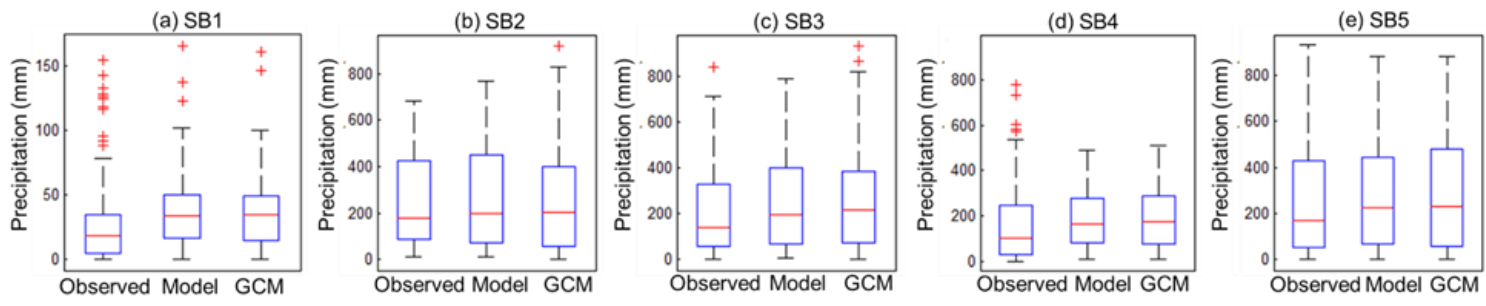

Figure 3. Comparison of observed precipitation, model generated and GCM precipitation for controlled scenario (1981-2000). Note: Red bar inside box represents the median, lower and upper horizontal bar of the box represents first and third quartile, respectively. Red markers represent the outliers.

present annual precipitation for RCP scenario with their respective GCM. The increase in precipitation over station 3 is calculated to be $2.19,5.72,6.74$ and $8.64 \%$ respectively for the increasing order of RCP scenarios. In station 4 increments for RCP2.6 to RCP8.5 is calculated to be 4.35, 3.45, 4.09 and $8.11 \%$ respectively. Changes in annual precipitation over station 5 are found to be positive with 2.13, 5.80, 6.07 and $10.37 \%$ for RCPs. It can be concluded from Figure 4 that the changes

Table 2. Magnitude of Change in Precipitation Indices during Historical Period (1980-2000)

\begin{tabular}{lccccc}
\hline & SB1 & SB2 & SB3 & SB4 & SB5 \\
\hline CDD & 0.65 & 1.00 & 0.00 & 0.05 & 0.03 \\
CWD & 0.04 & 0.17 & 0.29 & 0.50 & 0.00 \\
PRCPTOT & 3.20 & 0.42 & -3.13 & 17.57 & 0.09 \\
R1mm & 0.06 & -0.92 & -1.45 & -0.25 & -0.06 \\
R10mm & 0.21 & -0.44 & 0.00 & 1.42 & 0.05 \\
R20mm & 0.05 & -0.27 & 0.30 & 1.18 & 0.02 \\
R95p & 1.33 & 0.20 & -2.76 & 18.30 & -0.03 \\
R99p & 0.00 & 1.52 & 0.00 & 0.00 & -0.04 \\
SDII & 0.03 & 0.00 & 0.05 & 0.20 & 0.07 \\
\hline
\end{tabular}

in precipitation across the basin are positive with magnitude increasing from low RCP scenario to high RCP scenario.

\subsection{Changes in Extreme Precipitation Indices}

4.2.1. Trends in Precipitation Indices for Historical Period (1980 2000)

Trend analysis of historical data period gives an insight of existing pattern of the changing climate and also proves helpful for comparing the future changes. Figure 5 shows the z-statistics of indices for different stations and their respective Sen's slope magnitude are shown in Table 2. From the Figure 5 , it is clear that station 4 shows significant increasing trend for CWD, PRCPTOT, R10mm, R20mm, R95p and SDII, the magnitude of increase of these indices are shown in Table 2. No significant trend was observed at any station except station 4. Indices showing increasing or decreasing trend are not statistically significant at $95 \%$ confidence level. Average of the increase in annual precipitation of all stations show an increase of $3.63 \mathrm{~mm} /$ year which is not very much significant for the basin, whereas the contribution of very wet days (R95p) is likely to increase. The increasing trend of R95p shows that this increase can create a situation of frequent flood events. 

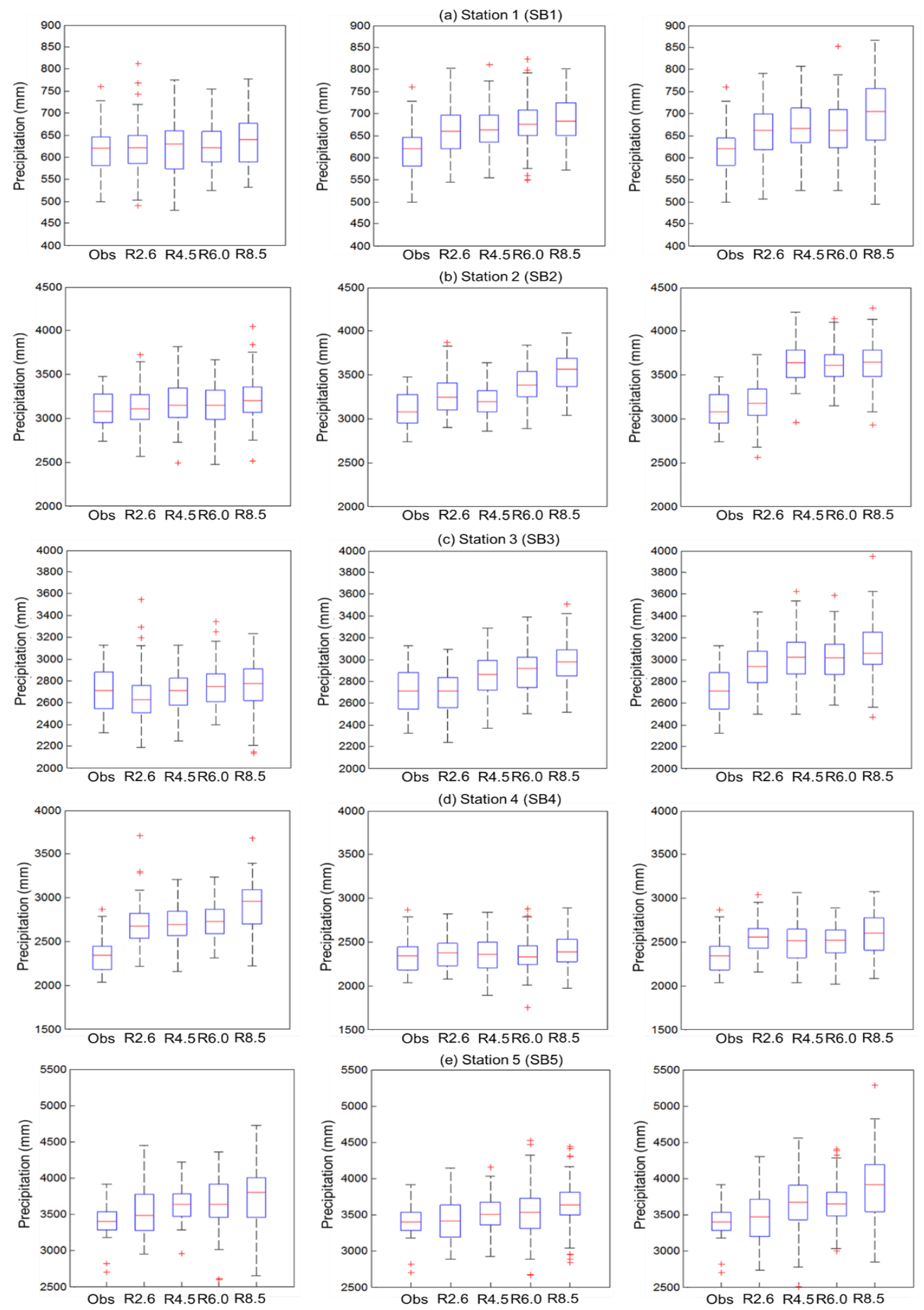

Figure 4. Boxplots of the precipitation anomalies for GCM/RCP scenarios over the period of 2011-2100 compared to observed precipitation for all stations.

\subsubsection{Trends in Annual Precipitation for Future Scenario}

Average of all stations annual precipitation gives an idea about the change in precipitation over the basin. Figure 6(a) represents the significant and non-significant trends in annual precipitation over the entire basin. Although on the 30-year time scale, some decreasing trend was found and it is statisti- cally non-significant at $95 \%$ confidence level. Significant increasing trend was observed for CM3-RCP2.6, CM3-RCP4.5, CM3-RCP6.0 and CM3-RCP8.5 for different time periods. The magnitude of change in different indices over all the stations for GCM/RCP scenarios were calculated for the long-term period of $2011 \sim 2100$ and three inter-decadal time 
Table 3. Magnitude of Change in Annual Precipitation (mm/decade), R1mm (days/decade), CDD (days/decade), Consecutive Wet Days (days/decade), R95p (mm/decade) and R99p (mm/decade) for Four RCP Scenarios of ESM2G Model

\begin{tabular}{|c|c|c|c|c|c|c|c|c|c|c|c|c|c|}
\hline & & SB1 & & & & SB2 & & & & SB3 & & & \\
\hline Indices & $\mathrm{RCP}$ & $\begin{array}{l}2011- \\
2100\end{array}$ & $\begin{array}{l}2011- \\
2040\end{array}$ & $\begin{array}{l}2041- \\
2070\end{array}$ & $\begin{array}{l}2071- \\
2100\end{array}$ & $\begin{array}{l}2011- \\
2100\end{array}$ & $\begin{array}{l}2011- \\
2040\end{array}$ & $\begin{array}{l}2041- \\
2070\end{array}$ & $\begin{array}{l}2071- \\
2100\end{array}$ & $\begin{array}{l}2011- \\
2100\end{array}$ & $\begin{array}{l}2011- \\
2040\end{array}$ & $\begin{array}{l}2041- \\
2070\end{array}$ & $\begin{array}{l}2071- \\
2100\end{array}$ \\
\hline \multirow[t]{4}{*}{ Prcptot } & 2.6 & 0.67 & 5.00 & -2.43 & 16.38 & 3.61 & 54.19 & 78.11 & -113.8 & 0.68 & 0.86 & 6.80 & -10 \\
\hline & 4.5 & -2.97 & -3.1 & -9.31 & -14.8 & 18.28 & 40.00 & -27.8 & 2.87 & 0.19 & -2.43 & -5.8 & 0.14 \\
\hline & 6.0 & 2.75 & 1.10 & 13.39 & 2.30 & 18.24 & 80.64 & -47.2 & -64.45 & 0.73 & -18.00 & 13.8 & 5.26 \\
\hline & 8.5 & -2.0 & -8.8 & -11.6 & 10.37 & 26.70 & -65.0 & 27.28 & 27.50 & 1.14 & 1.78 & 12.4 & -8.5 \\
\hline \multirow[t]{4}{*}{$\mathrm{R} 1 \mathrm{~mm}$} & 2.6 & 0.21 & -1.0 & 0.48 & 3.33 & -0.26 & -1.00 & 2.50 & -3.85 & 0.00 & 0.00 & 1.76 & -2.5 \\
\hline & 4.5 & 0.48 & 0.71 & -2.00 & -2.50 & 0.50 & 0.00 & -0.48 & 0.87 & 0.00 & -2.40 & -2.7 & -2.0 \\
\hline & 6.0 & 0.83 & 0.53 & 1.00 & 0.00 & 0.31 & 1.25 & -0.43 & -1.43 & 0.24 & -2.50 & 1.20 & 0.71 \\
\hline & 8.5 & 0.00 & -1.8 & -1.82 & 1.11 & 1.58 & -5.52 & 2.22 & 0.91 & 0.24 & -0.42 & 0.00 & -1.4 \\
\hline \multirow[t]{4}{*}{ CDD } & 2.6 & 0.00 & 0.00 & -0.43 & 0.83 & 0.00 & 0.50 & 1.58 & 2.00 & 0.00 & -4.35 & 1.67 & -0.5 \\
\hline & 4.5 & 0.00 & 0.00 & 1.50 & 1.43 & 0.00 & 0.00 & -1.67 & -2.61 & 0.00 & -1.00 & 0.87 & 1.00 \\
\hline & 6.0 & 0.15 & 0.83 & 1.60 & 2.50 & -0.43 & -0.95 & 1.00 & 0.00 & 0.67 & 1.25 & 6.67 & 1.74 \\
\hline & 8.5 & 0.00 & 2.63 & 0.00 & 1.36 & -0.38 & 0.42 & -0.45 & -0.59 & -0.17 & -0.91 & 0.00 & -1.2 \\
\hline \multirow[t]{4}{*}{ CWD } & 2.6 & 0.00 & 0.42 & -1.5 & 1.50 & 0.00 & 0.00 & 0.37 & -1.25 & 0.00 & 0.45 & 1.05 & -0.4 \\
\hline & 4.5 & 0.00 & 0.00 & 0.00 & -0.87 & 0.32 & 0.00 & 1.54 & -0.71 & -0.19 & -0.91 & -0.5 & -1.0 \\
\hline & 6.0 & 0.00 & 0.00 & 0.43 & 0.40 & 0.20 & 0.50 & 0.00 & 0.00 & 0.24 & -0.56 & 0.67 & 0.00 \\
\hline & 8.5 & 0.00 & 1.00 & 0.00 & 0.00 & 0.45 & -1.33 & 0.00 & 2.31 & 0.00 & 1.20 & 0.00 & -0.5 \\
\hline \multirow[t]{4}{*}{ R95p } & 2.6 & 0.83 & 1.33 & -15.7 & 7.33 & 4.26 & 67.65 & 10.00 & -41.36 & 1.11 & 8.30 & 2.92 & -4.0 \\
\hline & 4.5 & -2.63 & -0.4 & 1.88 & -6.40 & 12.82 & 11.15 & -4.28 & -21.85 & 1.00 & 2.60 & 1.00 & 2.20 \\
\hline & 6.0 & 0.51 & -2.5 & -6.53 & 0.92 & 16.47 & 60.92 & 61.48 & -6.83 & -0.71 & -3.27 & 1.17 & 0.78 \\
\hline & 8.5 & -3.27 & 2.93 & 0.11 & -9.45 & 7.82 & 42.36 & 9.85 & 1.42 & 0.62 & 1.67 & 8.50 & -5.2 \\
\hline \multirow[t]{4}{*}{ R99p } & 2.6 & 0.00 & 0.00 & 0.00 & -0.10 & 0.17 & 0.00 & -2.22 & 7.38 & 0.00 & 0.00 & 0.00 & 0.00 \\
\hline & 4.5 & 0.00 & 0.00 & 0.83 & 0.00 & 0.26 & 3.33 & 2.92 & 3.50 & 0.00 & 0.00 & 0.00 & 0.00 \\
\hline & 6.0 & 0.00 & 0.00 & 0.13 & 0.00 & 0.96 & -1.71 & 20.00 & -8.79 & 0.00 & -3.67 & 0.00 & 0.13 \\
\hline & 8.5 & 0.00 & 0.47 & 0.00 & 0.00 & 1.07 & 2.68 & 0.00 & 23.07 & 0.00 & 0.00 & 1.75 & 0.00 \\
\hline
\end{tabular}

scales (i.e. $2011 \sim 2040,2041 \sim 2070,2071 \sim 2100$ ). For representation, Sen's slope magnitude of annual precipitation and number of rainy days (for ESM2G model) is shown in Table 3 for all the RCP scenarios. The maximum positive change was found at station 5 for the time period during 2041 $\sim 2070$ with the magnitude of $138 \mathrm{~mm} /$ decade whereas maximum decrease is recorded at SB5 during the period of 2071 2100 for RCP2.6. At station 1, an increase in annual precipitation is observed over all the timescale and maximum increase found for RCP8.5 which ranges from $29.14 \mathrm{~mm} /$ decade (2011 2040) to $30.55 \mathrm{~mm} /$ decade (2071 2100). Average annual precipitation for the entire basin shows increasing trend for all the RCP scenarios with magnitude of $2.31 \mathrm{~mm}$ to $31.51 \mathrm{~mm} /$ decade. GCM models show uncertainty in the magnitude of changes in annual precipitation and GFDL-CM3 model shows the higher magnitude of changes as compared to the other two models.

\subsubsection{Trends in the Distribution of Precipitation}

Figure $6 \mathrm{~b}, 6 \mathrm{c}$, and $6 \mathrm{~d}$ represents the Mann-Kendall z-statistics of consecutive dry days (CDD), consecutive wet days (CWD), and number of rainy days (R1mm) over the basin for different GCM RCP scenario during different time periods. Consecutive dry days index represents the longest spell of days without any precipitation $(>1 \mathrm{~mm})$ events. For the long-term period (2011 2100) no significant trend is observed over the basin. Trend analysis of 30-year time scales (2011 2040, $2041 \sim 2070$ and $2071 \sim 2100)$ represent a sig-

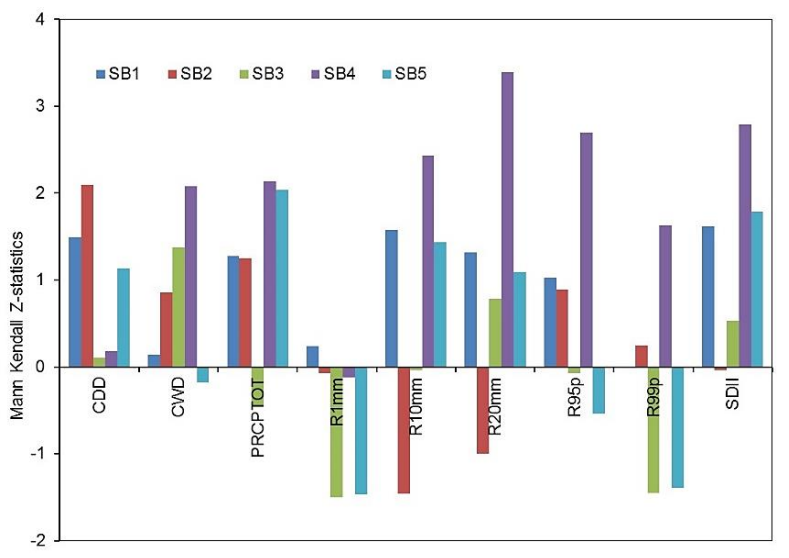

Figure 5. Mann-Kendall test Z-statistics of precipitation indices during historical period (1980-2000) over all the stations.

nificant increasing trend for $2071 \sim 2100$ in model CM3 RCP2.6 as shown in Figure 6b. The magnitude of change (Sen's slope) at sub-basin scale for CDD can be seen in Table 3 for ESM2G model. Maximum change in CDD was found to be positive with 8.46 days/decade in station 1 for CM3 RCP2.6 scenario during the period of $2071 \sim 2100$, likewise, maximum decreasing trend of CDD observed in station 3 with magnitude 4.35 days/decade for the RCP2.6 scenario. Average of three GCMs for RCP scenarios show an increase of 3.46 day/decade at station 1 and at stations 2, 3, 4 and 5 increase in 
Table 3. Magnitude of Change in Annual Precipitation ( $\mathrm{mm} /$ decade), R1mm (days/decade), CDD (days/decade), Consecutive Wet Days (days/decade), R95p (mm/decade) and R99p (mm/decade) for Four RCP Scenarios of ESM2G Model (Continued)

\begin{tabular}{|c|c|c|c|c|c|c|c|c|c|}
\hline & & SB4 & & & & SB5 & & & \\
\hline Indices & $\mathrm{RCP}$ & $2011-2100$ & $2011-2040$ & $2041-2070$ & $2071-2100$ & $2011-2100$ & $2011-2040$ & $2041-2070$ & $2071-2100$ \\
\hline \multirow[t]{4}{*}{ Prcptot } & 2.6 & 5.00 & 36.64 & -10.6 & -71.1 & -1.38 & 123.94 & -0.04 & -196.3 \\
\hline & 4.5 & 10.79 & 97.86 & 76.72 & -38.2 & 1.44 & -9.87 & 16.00 & -57.75 \\
\hline & 6.0 & 23.47 & 57.54 & 67.64 & 11.60 & 23.96 & 80.90 & 29.00 & 67.60 \\
\hline & 8.5 & 34.67 & -151.5 & -18.7 & 2.85 & 54.72 & -68.03 & -35.67 & 66.00 \\
\hline \multirow[t]{4}{*}{$\mathrm{R} 1 \mathrm{~mm}$} & 2.6 & 0.26 & -0.50 & -1.11 & -3.13 & 0.15 & 1.82 & 0.71 & -3.33 \\
\hline & 4.5 & 0.77 & 0.00 & 2.50 & -3.08 & 0.33 & 0.00 & 2.00 & 0.00 \\
\hline & 6.0 & 1.14 & 0.59 & 2.73 & 0.00 & 0.00 & -1.54 & -3.85 & 3.04 \\
\hline & 8.5 & 1.54 & -6.82 & -2.00 & 1.43 & 1.05 & 0.00 & 0.00 & 0.00 \\
\hline \multirow[t]{4}{*}{ CDD } & 2.6 & 0.00 & -1.67 & 0.74 & 1.50 & -0.26 & -0.91 & 0.83 & 0.56 \\
\hline & 4.5 & 0.00 & 1.36 & 0.00 & -0.48 & 0.00 & 2.86 & -0.77 & -1.00 \\
\hline & 6.0 & 0.37 & 0.77 & 0.00 & 0.67 & 0.53 & 0.77 & 0.53 & -5.22 \\
\hline & 8.5 & 0.00 & -0.91 & 1.25 & 0.40 & 0.00 & 2.78 & 1.00 & 3.33 \\
\hline \multirow[t]{4}{*}{ CWD } & 2.6 & 0.00 & 0.71 & 0.00 & 0.00 & 0.00 & 0.00 & -0.50 & -0.71 \\
\hline & 4.5 & 0.15 & 0.00 & 1.33 & 0.00 & 0.00 & 0.00 & -0.59 & -0.77 \\
\hline & 6.0 & 0.19 & 0.00 & 0.00 & 0.00 & 0.00 & 0.00 & 0.00 & 0.00 \\
\hline & 8.5 & 0.00 & -1.20 & -0.38 & -0.83 & 0.00 & -0.77 & -0.50 & 0.00 \\
\hline \multirow[t]{4}{*}{ R95p } & 2.6 & 7.72 & 18.56 & 15.94 & -2.55 & -6.92 & 43.09 & -5.31 & -133.3 \\
\hline & 4.5 & 4.84 & 52.53 & 42.50 & 13.27 & -10.6 & -18.00 & 55.81 & -0.23 \\
\hline & 6.0 & 10.82 & 6.09 & 34.78 & 1.93 & 20.05 & 14.08 & 120.11 & -0.47 \\
\hline & 8.5 & 20.46 & -7.38 & 33.21 & -3.00 & 34.53 & -77.53 & -21.58 & 29.05 \\
\hline \multirow[t]{4}{*}{ R99p } & 2.6 & 2.05 & 1.07 & -2.58 & 28.23 & 0.00 & -10.13 & 0.00 & -25.50 \\
\hline & 4.5 & 1.97 & 0.00 & -13.8 & 5.22 & -0.53 & -21.00 & 17.40 & 1.89 \\
\hline & 6.0 & 2.40 & 0.47 & 27.07 & -3.20 & 1.19 & 0.00 & 29.91 & 0.00 \\
\hline & 8.5 & 0.75 & 0.00 & 0.00 & -26.2 & 8.84 & 0.00 & 1.50 & -17.18 \\
\hline
\end{tabular}
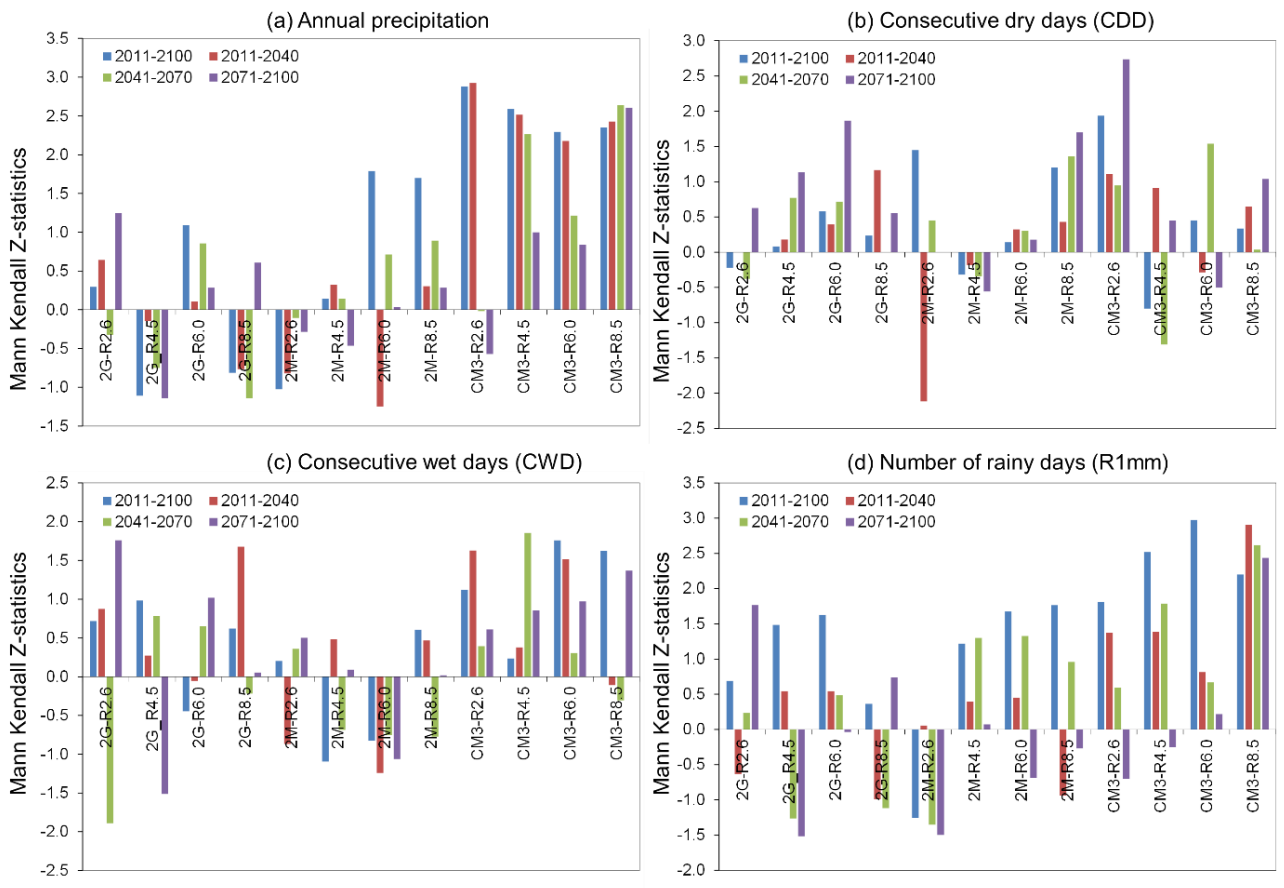

Figure. 6 Mann-Kendall test Z-statistics of indices indicating the distribution of precipitation for all the GCM/RCP ensembles.

consecutive dry days are not significant in magnitude.

Z-statistics of CWD trends show no significant increase over the period of $2011 \sim 2100$ as shown in Figure 6(c). The maximum positive trend in CWD was observed in station 1 with the magnitude of 3.81 days/decade for period of 2011 2040 under the CM3 RCP2.6 scenario. Average of GCM values for respective RCPs shows no large magnitude increase or decrease in CWD. Figure 6(d) shows z-statistics for number 
(a) R10mm

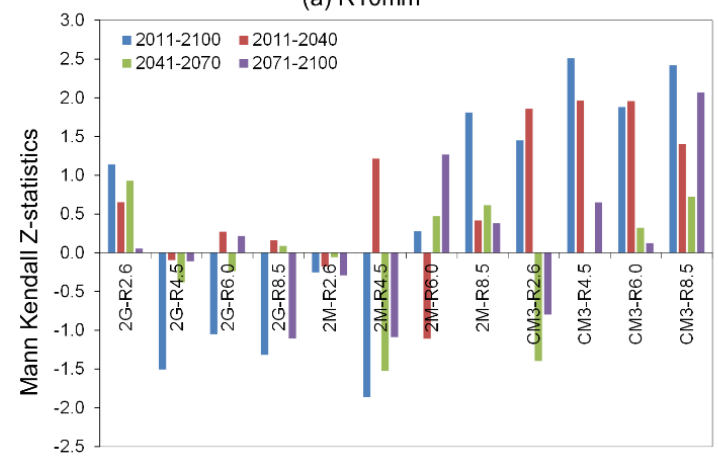

(c) R95p

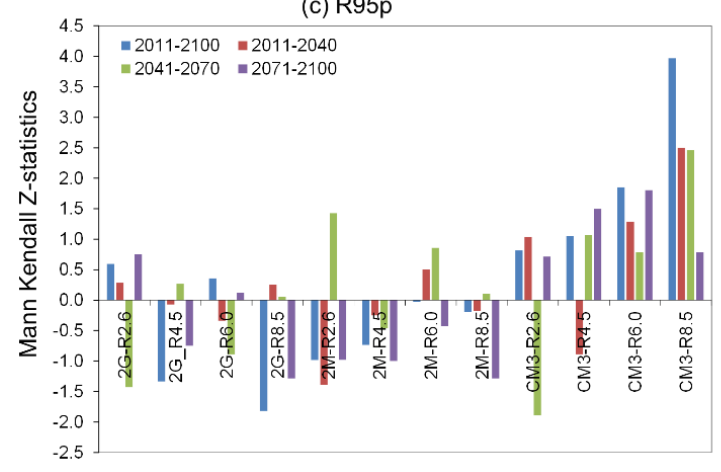

(b) $\mathrm{R} 20 \mathrm{~mm}$

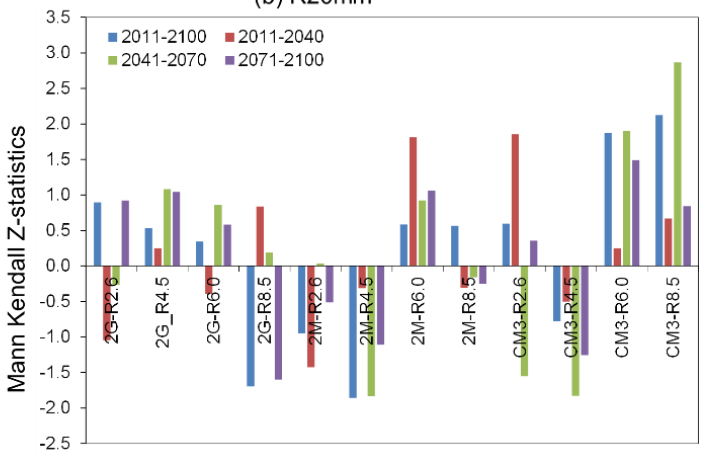

(d) R99p

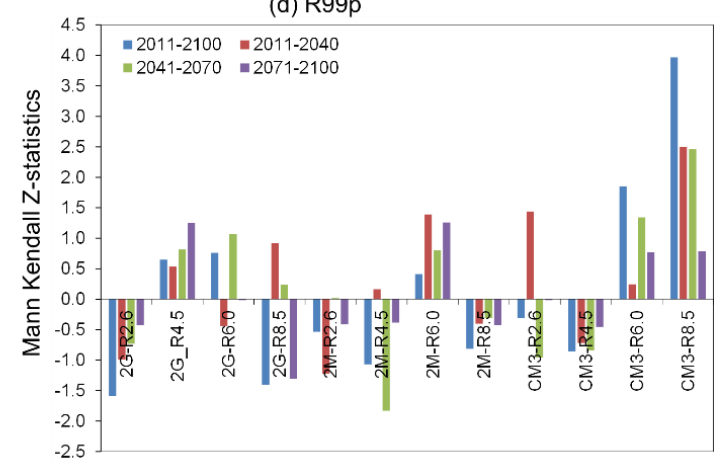

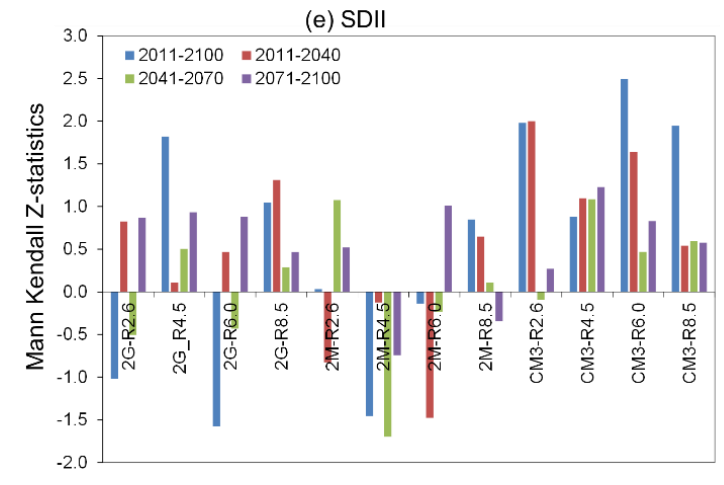

Figure 7. Mann-Kendall test Z-statistics of indices indicating the intensity of precipitation for all the GCM/RCP ensembles.

of rainy days and it is evident that the trend is significantly increasing for CM3 RCP4.5 and CM3 RCP8.5 of the GCM RCP scenario.

\subsubsection{Trends in the Intensity of Precipitation}

Number of heavy precipitation days $(\mathrm{R} 10 \mathrm{~mm})$ is the number of days with precipitation more than $10 \mathrm{~mm}$ whereas number of very heavy precipitation days (R20mm) defined as number of days with precipitation more than $20 \mathrm{~mm}$. Z-statistics of R10mm shows increasing trend over the basin for CM3 RCP4.5 and CM3 RCP 8.5 for different time scales as shown in Figure 7(a). Whereas Z-statistics test of index R20mm indicates significant increasing trends for CM3 RCP8.5 for the period of $2011 \sim 2100$ and $2041 \sim 2070$ (Figure 7b). Very wet days precipitation (R95p) are the sum of the precipitation of days when precipitation was more than 95 th percentile of the wet day precipitation distribution derived over base period and extremely wet days precipitation (R99p) defined as amount of precipitation received from the days when precipitation was more than 99th percentile of the wet day precipitation derived over the base period. These two indices provide an idea of the contribution of very wet days and extremely wet days precipitation to the annual precipitation. Figure 7c represents Z-statistics of R95p and it shows a significant increasing trend for CM3 RCP8.5 over the period of $2011 \sim 2100,2011 \sim 2040$ and $2041 \sim 2070$. In the case of R99p significant increasing trend is observed for a long-term period of $2011 \sim 2100$ for CM3 RCP6.0 and over the period of $2011 \sim 2100,2011 \sim 2040$ and $2041 \sim 2070$ as shown in Figure $7 d$. Z-statistics of SDII trend analysis is shown in Figure 7e which shows a significant increasing trend for CM3 RCP6.0. The maximum increase of $97 \mathrm{~mm} /$ decade at station 4 for CM3 RCP6.0 whereas a maximum decrease is observed at 

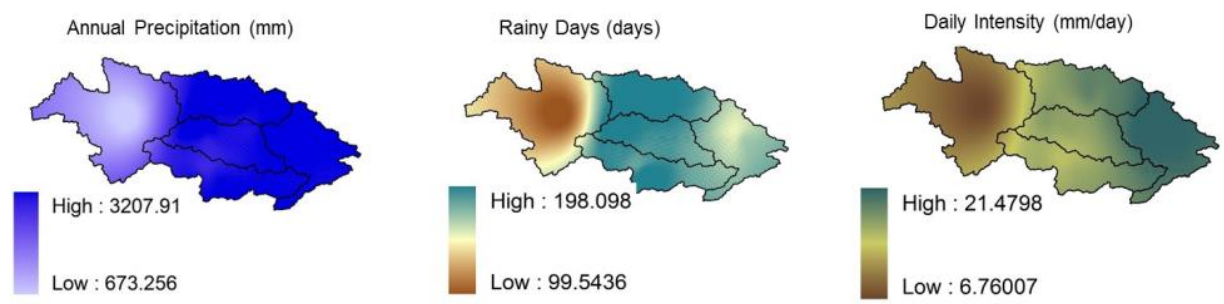

Figure 8. Spatiotemporal distribution of precipitation indices for observed period (1980-2000) annual precipitation (mm), rainy days (days) and intensity of precipitation ( $\mathrm{mm} /$ day).
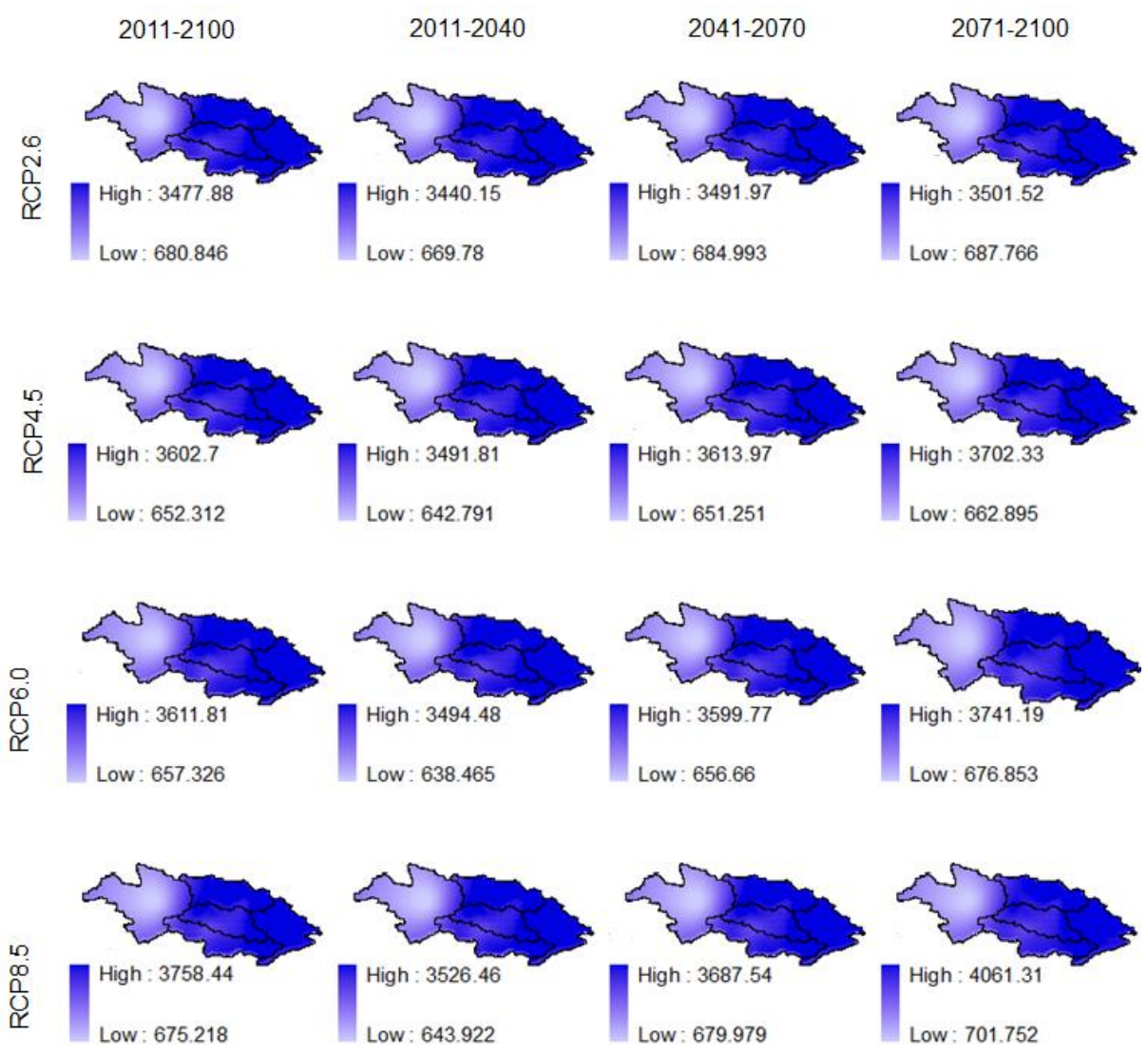

Figure 9. Spatio-temporal variation of annual precipitation over the basin for RCP scenarios.

station 5 for ESM2G R2.6 (Table 3) during the period of 2071 $\sim 2100$ with a magnitude of $133.35 \mathrm{~mm} /$ decade. Similarly, Sen's slope analysis results of R99p shows that for long-term (2011 2100) duration no significant magnitude change is found in basin but maximum magnitude of decrease observed as $46 \mathrm{~mm} /$ decade at station 2 during $2011 \sim 2040$ followed by maximum increase of $46.91 \mathrm{~mm} /$ decade for extreme scenario (RCP8.5) over station 5 at the end of the century (2071 2100). Table 3 represents the Sens's slope magnitude of the precipitation indices of ESM2G model for four RCP scenarios.

\subsubsection{Spatiotemporal Distribution of Precipitation Indices}

Spatiotemporal distribution of indices PRCPTOT, R1mm, SDII for the historical period (Figure 8) and average of the three GCMs for RCP scenarios at different time scale are shown in Figures 9, 10 and 11. Figure 8 shows the spatial distribution of annual precipitation, number of rainy days in a year and daily intensity of precipitation for the observed time period $(1980 \sim 2000)$. It is observed from the historical data analysis of the precipitation that annual precipitation in the basin ranges from $673.25 \mathrm{~mm}$ to $3207.91 \mathrm{~mm}$, whereas number of rainy days in a year varies from 99 days to 198 days and daily intensity of the precipitation varies from 6.7 $\mathrm{mm}$ /day to $21.47 \mathrm{~mm} /$ day, spatial distribution of these indices are shown in Figure 8. It is evident from Figure 9 that amount of annual precipitation is increasing at different 30-year time scale and also on the long-term duration of $2011 \sim 2100$ over entire basin for the RCP scenarios. Figure 10 represents the spatial variation of number of rainy days over the basin for 

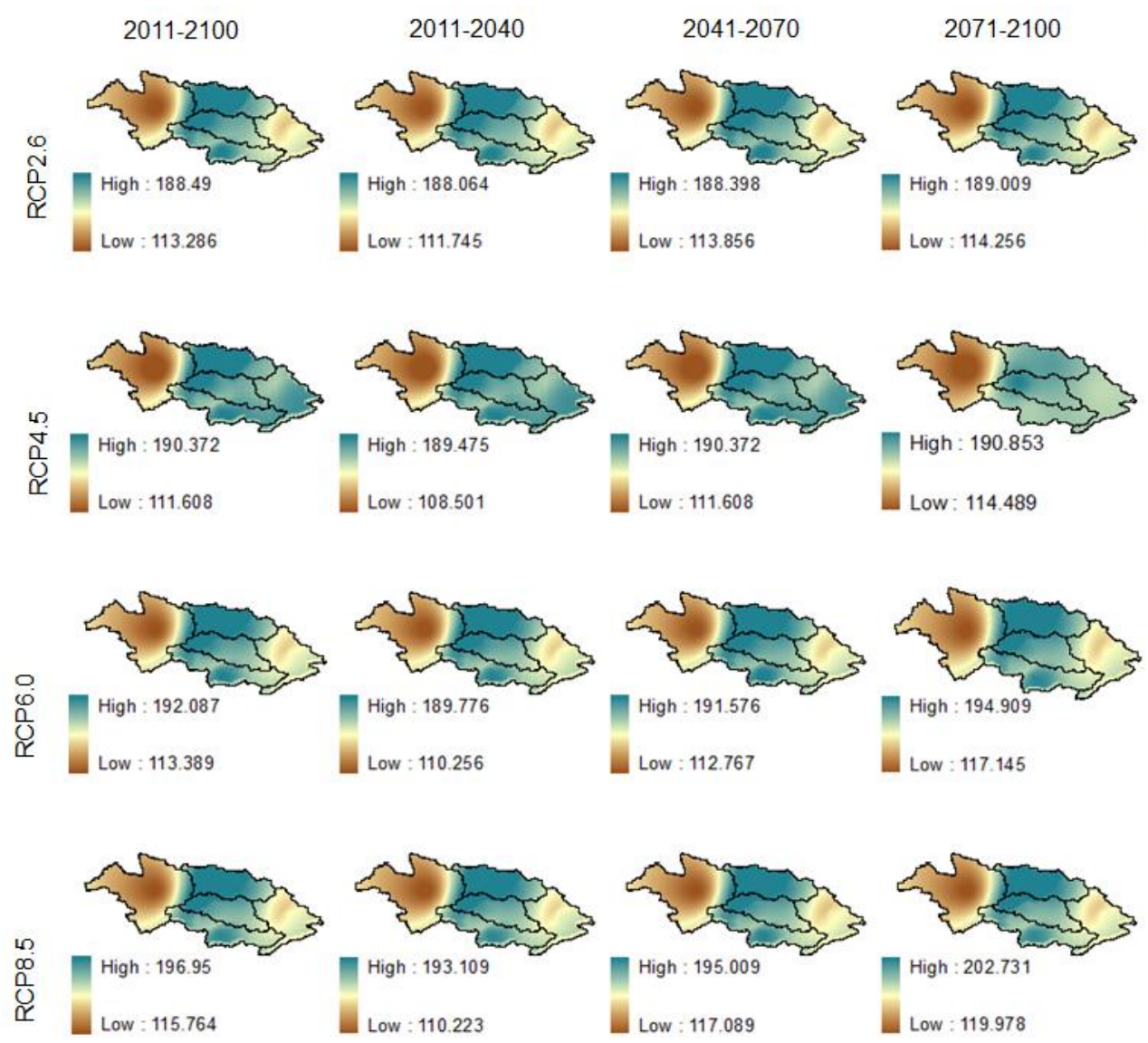

Figure 10. Spatio-temporal distribution of number of rainy days $(\mathrm{R} 1 \mathrm{~mm})$ over the basin for RCP scenarios.

different timescale and RCP scenario. R1mm is likely to decrease when compared to historical period values, as during historical period $\mathrm{R} 1 \mathrm{~mm}$ ranges from minimum 99 days to maximum of 198 days but in future RCP scenarios R1mm reflects decreasing trend in lower part whereas increasing in the upper station i.e. station 1 . Since the spatiotemporal analysis of annual precipitation and number of rainy days indicate an increase in precipitation and decrease in rainy days, it represents that the intensity is likely to increase in the future scenarios. Figure 11 represents the SDII variation on the spatiotemporal domain for the basin. Historical period SDII variation shows the range from 6.7 to $21.47 \mathrm{~mm}$ /days (Figure 8 ), whereas for future scenarios it shows an increase in intensity up to $29.5 \mathrm{~mm} /$ day for RCP8.5 followed by the decrease in the upper portion. The decrease in the number of rainy days depicts the increase in daily precipitation intensity index for all the RCP scenarios over the stations except the station 1. Decrease in SDII over station 1 is followed by the increase of number of rainy days as shown in Figure 11 whereas station 2, station 3, station 4 and station 5 where number of rainy days is likely to decrease are prone to increase in daily rainfall intensity. Variation of daily intensity for RCPs over interdecadal periods are shown in Figure 11. Temporal variation of SDII indicates a direct proportionality to the emission scenario as the value of daily intensity is increasing from low to high emi- ssion scenario. The magnitude of increase in SDII ranges from $24 \mathrm{~m} /$ day up to $29.59 \mathrm{~mm} /$ day for RCP4.5 and RCP8.5, respectively.

\section{Conclusions}

Precipitation downscaling and precipitation indices analysis for $2011 \sim 2100$ was performed using three GCM datasets for four RCP scenarios. Average of precipitation generated using three GCMs gives a clear picture of increasing trend of annual precipitation and intensity in Subansiri river basin. Subansiri river originates from Tibetan plateau which is rain shadow zone and receives less than thousand millimeter precipitation whereas precipitation in stations station 2, station 3, station 4 and station 5 which fall in Arunachal Pradesh and Assam states receive high annual precipitation in thousands of millimeters. The study reveals the possibility of increase in annual precipitation and intensity in station 1 which is in agreement with a previous study (Song et al., 2011). Changes in annual precipitation magnitude vary for RCP2.6, RCP4.5, RCP6.0 and RCP8.5 from 3.26, 5.58, 6.39 and $9.57 \mathrm{~mm} /$ year, respectively. IPCC (2013) report indicates an increase in annual precipitation for the mountainous region which justifies the findings of the study. Physical reasons behind the probable change were not the part of the study but 

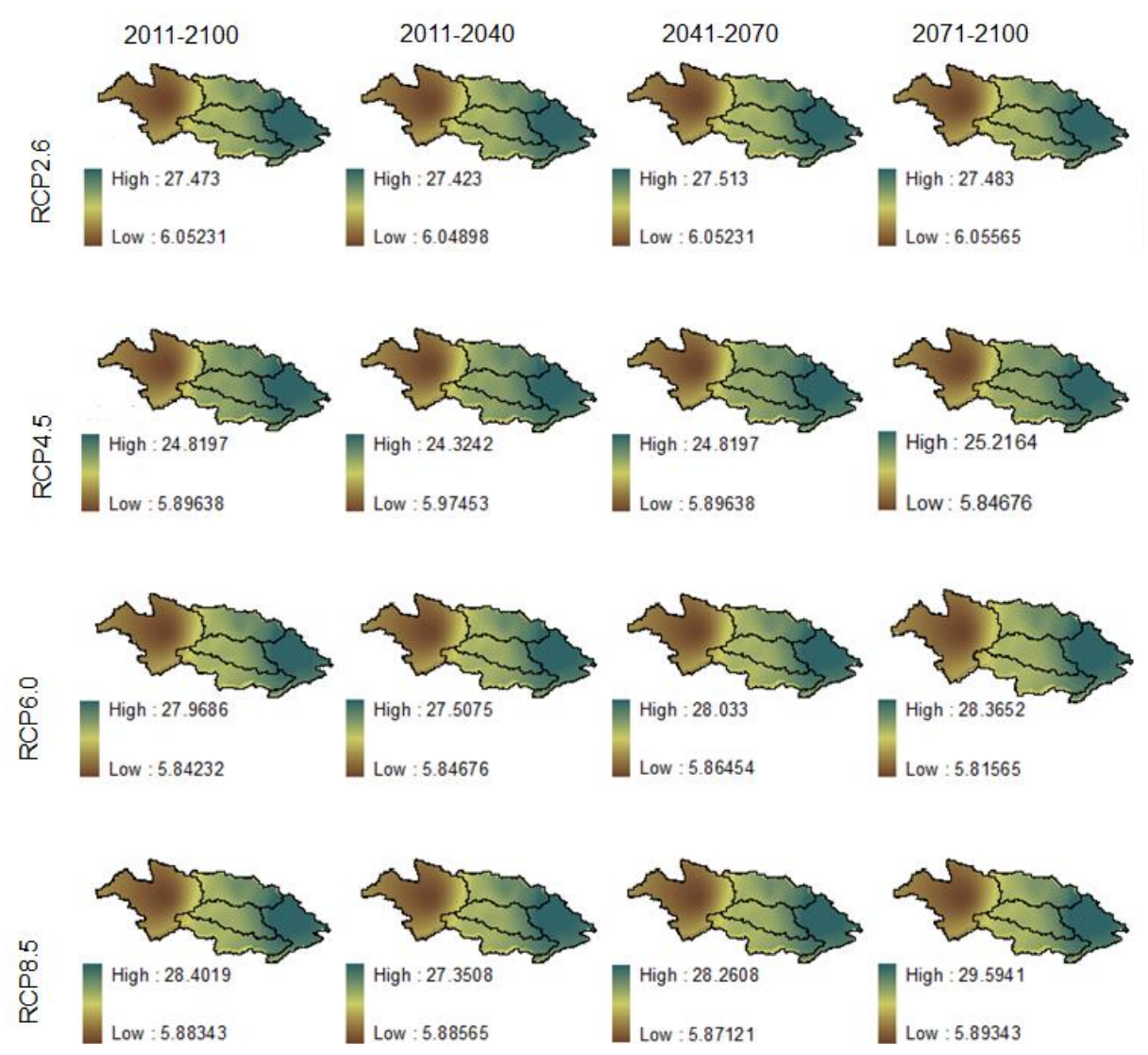

Figure 11. Spatio-temporal distribution of precipitation intensity (SDII) over the basin for RCP scenarios.

the results show a good agreement with the previous studies done in the region and ongoing possible greenhouse gas emission scenarios. Though the present study focuses mainly on Subansiri river catchment in the eastern Himalayan region. Many other river catchments in eastern Himalayan regions shares the same hydro-climatology, for example, all are fed by Southwest Monsoon during the same period of the year and have same wind circulation patterns. Hence, the outcomes of this study can be related to the climatic changes happening in other catchments in the region.

\section{References}

Alexander, L.V., Zhang, X, and Peterson, T.C. et al. (2006). Global observed changes in daily climate extremes of temperature and precipitation. J. Geophys. Res., 111, D05109. https://doi.org/10.10 29/2005JD006290

Allen, M.R., and Ingram, W.J. (2002). Constraints on future changes in climate and the hydrologic cycle. Nature, 419(6903), 224-232. https://doi.org/10.1038/nature01092

Anandhi, A., Srinivas, V.V., Nanjundiah, R.S., and Kumar, D.N. (2008). Downscaling precipitation to river basin in India for IPCC SRES scenarios using supportl vector machine. Int. J. Climatol., 28(3), 401-420. https://doi.org/10.1002/joc.1529

Berg, P., Haerter, J.O., Thejll, P., Piani, C., Hagemann, S., and Christensen J.H. (2009). Seasonal characteristics of the relationship between daily precipitation intensity and surface tempe- rature. J. Geophys. Res., 114, D18102. https://doi.org/10.1029/20 09JD012008

Burn, D.H., and Elnur, M.A.H. (2002). Detection of hydrologic trends and variability. J. Hydrol., 255(1-4), 107-122. https://doi. org/10.1016/S0022-1694(01)00514-5

Chu, J.T., Xia, J., and Xu, C.Y. (2008). Suitability analysis of SDSM model in the Haihe River Basin. Resour. Sci., 30(12), 1825-1832.

Das, A., Ghosh, P.K., Choudhury, B.U., Patel, D.P., Munda, G.C., Ngachan, S.V., and Chowdhury, P. (2009). Climate change in North East India: recent facts and events-worry for agricultural management, Proc. of the Workshop on Impact of Climate Change on Agriculture, pp. 32-37.

Deka, R.L., Mahanta, C., Pathak, H., Nath, K.K., and Das, S. (2013). Trends and fluctuations of rainfall regime in the Brahmaputra and Barak basins of Assam, India. Theor. Appl. Climatol., 114(1-2), 61-71. https://doi.org/10.1007/s00704-012-0820-x

Dettinger, M.D., Cayan, D.R., Meyer, M.K., and Jeton, A.E. (2004). Simulated hydrologic responses to climate variations and change in the Merced, Carson, and American River basins, Sierra Nevada, California, 1900-2099. Clim. Change, 62(1-3), 283-317. https:// doi.org/10.1023/B:CLIM.0000013683.13346.4f

Donat, M.G., Alexander, L.V., Yang, H., Durre, I., Vose, R., and Caesar, J. (2013). Global land-based datasets for monitoring climatic extremes. Bull. Am. Meteorol. Soc., 94(7), 997-1006. https://doi.org/10.1175/BAMS-D-12-00109.1

Duhan, D., and Pandey, A. (2013). Statistical analysis of long term spatial and temporal trends of precipitation during 1901-2002 at Madhya Pradesh, India. Atmos. Res., 122, 136-149. https:// doi.org/10.1016/j.atmosres.2012.10.010 
Duhan, D., and Pandey, A. (2014). Statistical downscaling of temperature using three techniques in the Tons River basin in Central India. Theor. Appl. Climatol., 121(3-4), 605-622. https://doi.org/ 10.1007/s00704-014-1253-5

Ghosh, S., and Mujumdar, P.P. (2008). Statistical downscaling of GCM simulations to stream flow using relevance vector machine. Adv. Water Resour., 31(1), 132-146. https://doi.org/10.1016/j.adv watres.2007.07.005

Goyal, M.K. (2014). Statistical analysis of long term trends of rainfall during 1901-2002 at Assam, India. Water Resour. Manage., 28(6), 1501-1515. https://doi.org/10.1007/s11269-014-0529-y

Goyal, M.K., and Ojha, C.S.P. (2012). Downscaling of precipitation on a lake basin: evaluation of rule and decision tree induction algorithms. Hydrol. Res., 43(3), 215-230. https://doi.org/10.2166/ nh.2012.040

Goyal, M.K., and Khan, M. (2016). Assessment of spatially explicit annual water-balance model for Sutlej river basin in eastern Himalayas and Tungabhadra river basin in peninsular India Hydrol. Res., 48(2), 542-558. https://doi.org/10.2166/nh.2016.053

Goyal, M.K., and Sharma, A. (2016). A fuzzy c-means approach regionalization for analysis of meteorological drought homogeneous regions in western India. Nat. Hazards, 84(3) 1831-1847. https://doi.org/10.1007/s11069-016-2520-9

Grotch, S.L., and MacCracken, M.C. (1991). The use of general circulation models to predict regional climatic change. J. Clim., 4(3), 286-303. https://doi.org/10.1175/1520-0442(1991)004<0286: TUOGCM $>2.0 . \mathrm{CO} ; 2$

Hashmi, M.Z., Shamseldin, A.Y., and Melville, B.W. (2011). Comparison of SDSM and LARS-WG for simulation and downscaling of extreme precipitation events in a watershed. Stochastic Environ. Res. Risk Assess., 25(4), 475-484. https:// doi.org/10.1007/s00477-010-0416-X

Huang, J., Sun, S., Xue, Y., Li, J., and Zhang, J. (2014). Spatial and temporal variability of precipitation and dryness/wetness during 1961-2008 in Sichuan Province, West China. Water Res. Manage., 28(6), 1655-1670.

IPCC (2007). Summary for policymakers of climate change 2007: the Physical science basis. Contribution of Working Group I to the Fourth Assessment Report of the Intergovernmental Panel on Climate Change, Cambridge University Press, Cambridge.

IPCC, (2013). The physical science basis. Working Group I Contribution to the Fifth Assessment Report of the Intergovernmental Panel on Climate Change, Cambridge University Press, Cambridge, UK and New York, USA.

IPCC, (2014). Climate change 2014: synthesis report. Contribution of Working Groups I, II and III to the Fifth Assessment Report of the Intergovernmental Panel on Climate Change IPCC. Geneva, Switzerland.

Jain, S.K., Kumar, V., and Saharia, M. (2013). Analysis of rainfall and temperature trends in northeast India. Int. J. Climatol., 33(4), 968-978. https://doi.org/10.1002/joc.3483

Jhajharia, D., Dinpashoh, Y., Kahya, E., Singh, V.P., and Fakheri-Fard, A. (2012). Trends in reference evapotranspiration in the humid region of northeast India. Hydrol. Process., 26(3), 421-435. https://doi.org/10.1002/hyp.8140

Kannan, S., and Ghosh, S. (2011). Prediction of daily rainfall state in a river basin using statistical downscaling from GCM output. Stochastic Environ. Res. Risk Assess., 25(4), 457-474. https:// doi.org/10.1007/s00477-010-0415-y

Katz, R.W., and Brown, B.G. (1992). Extreme events in a changing climate: variability is more important than averages. Clim. Change, 21(3), 289-302. https://doi.org/10.1007/BF00139728

Kendall, M.G. (1975). Rank Correlation Methods, Griffin and Co, London.
Khan, M.S., Coulibaly, P., and Dibike, Y. (2006). Uncertainty analysis of statistical downscaling methods. J. Hydrol., 319(1-4), 357-382. https://doi.org/10.1016/j.jhydrol.2005.06.035

Mahmood, R., and Babel, M.S. (2013). Evaluation of SDSM developed by annual and monthly sub-models for downscaling temperature and precipitation in the Jhelum basin, Pakistan and India. Theor. Appl. Climatol., 113(1-2), 27-44. https://doi.org/ 10.1007/s00704-012-0765-0

Mann, H.B., (1975). Nonparametric tests against trend. Econometrica, 13(3), 245-259.

Meenu, R., Rehana, S., and Mujumdar, P.P. (2013). Assessment of hydrologic impacts of climate change in Tunga-Bhadra river basin, India with HEC-HMS and SDSM. Hydrol. Process., 27(11), 1572-1589. https://doi.org/10.1002/hyp.9220

Mondal, A., and Mujumdar, P.P. (2012). On the basin-scale detection and attribution of human-induced climate change in monsoon precipitation and stream flow. Water Resour. Res., 48(10). https:// doi.org/10.1029/2011WR011468

Moss, R.H., Edmonds, J.A., Hibbard, K.A., Manning, M.R., Rose, S.K., Van Vuuren, D.P., Carter, T.R., Emori, S., Kainuma, M., Kram, T. and Meehl, G.A., (2010). The next generation of scenarios for climate change research and assessment. Nature, 463(72 82), 747-756. https://doi.org/10.1038/nature08823

Pingale, S.M., Khare, D., Jat, M.K., and Adamowski, J. (2014). Spatial and temporal trends of mean and extreme rainfall and temperature for the 33 urban centers of the arid and semi-arid state of Rajasthan. India. Atmos. Res., 138(1), 73-90. https://doi.org/ 10.1016/j.atmosres.2013.10.024

Prudhomme, C., Jakob, D., and Svensson, C. (2003). Uncertainty and climate change impact on the flood regime of small UK catchments. J. Hydrol., 277(1-2), 1-23. https://doi.org/10.1016/ S0022-1694(03)00065-9

Rahmani, M.A., and Zarghami, M. (2015). The use of statistical weather generator, hybrid data driven and system dynamics models for water resources management under climate change. J. Environ. Inf., 25(1), 23-35. https://doi.org/10.3808/jei.201400285

Rajeevan, M., Bhate, J., Kale, J.D., and Lal, B. (2006). High resolution daily gridded rainfall data for the Indian region: Analysis of break and active monsoon spells. Curr. Sci., 91(3), 296-306.

Sarma, B., Sarma, A.K., and Singh, V.P. (2013). Optimal ecological management practices (EMPs) for minimizing the impact of climate change and watershed degradation due to urbanization. Water Resour. Manage., 27(11), 4069-4082. https://doi.org/10.10 07/s11269-013-0396-y

Sen, P.K. (1968). Estimates of the regression coefficient based on Kendall's tau. J. Am. Stat. Assoc., 63(324), 1379-1389. https:// doi.org/10.2307/2285891

Shivam, Goyal, M.K., and Sarma A.K. (2016). Analysis of the change in temperature trends in Subansiri River basin for RCP scenarios using CMIP5 datasets. Theor. Appl. Climatol., 1-13.

Sillmann, J., Kharin, V.V., Zhang, X., Zwiers, F.W., and Bronaugh, D. (2013). Climate extremes indices in the CMIP5 multimodel ensemble: Part 1. Model evaluation in the present climate. J. Geophys. Res. Atmos., 118(4), 1716-1733. https://doi.org/10.1002/ jgrd.50203

Song, Y., Achberger, C., and Linderholm, H.W. (2011). Rain-season trends in precipitation and their effect in different climate regions of China during 1961-2008. Environ. Res. Lett., 6(3), 034025. https://doi.org/10.1088/1748-9326/6/3/034025

Swain, D.K., and Thomas, D. (2010). Climate change impact assessment and evaluation of agro-adaptation measures for rice production in eastern India. J. Environ. Inf., 16(2), 94-101. https:// doi.org/10.3808/jei.201000181 
Taylor, K.E., Stouffer, R.J., and Meehl, G.A. (2012). An overview of CMIP5 and the experiment design. Bull. Am. Meteorol. Soc., 93(4), 485-498. https://doi.org/10.1175/BAMS-D-11-00094.1

Valipour, M. (2012). Critical areas of Iran for agriculture water management according to the annual rainfall. Eur. J. Sci. Res., 84(4), 600-608.

Valipour, M. (2014). Comparative evaluation of radiation-based methods for estimation of potential evapotranspiration. J. Hydrol. Eng., 20(5), 04014068. https://doi.org/10.1061/(ASCE)HE.19435584.0001066

Valipour, M. (2015). Long-term runoff study using SARIMA and ARIMA models in the United States. Meteorol. Appl., 22(3), 592-598. https://doi.org/10.1002/met.1491

Valipour, M. (2016). Optimization of neural networks for precipitation analysis in a humid region to detect drought and wet year alarms. Meteorol. Appl., 23(1), 91-100. https://doi.org/10. 1002/met. 1533

Valipour, M., and Eslamian, S. (2014). Analysis of potential evapotranspiration using 11 modified temperature-based models Int. J. Hydrol. Sci. Technol., 4(3), 192-207. https://doi.org/10.15 04/IJHST.2014.067733

Valipour, M., Banihabib, M.E., and Behbahani, S.M.R. (2013). Comparison of the ARMA, ARIMA, and the autoregressive artificial neural network models in forecasting the monthly inflow of Dez dam reservoir. J. Hydrol., 476(7), 433-441. https://doi.org/ 10.1016/j.jhydrol.2012.11.017
Vano, J.A., Scott, M.J., Voisin, N., Stöckle, C.O., Hamlet, A.F., Mickelson, K.E., Elsner, M.M. and Lettenmaier, D.P., (2010). Climate change impacts on water management and irrigated agriculture in the Yakima River Basin, Washington, USA. Clim. Change, 102(1-2), 287-317. https://doi.org/10.1007/s10584-010-98 $56-\mathrm{z}$

Wilby, R.L., and Wigley, T.M.L. (2000). Precipitation predictors for downscaling: observed and general circulation model relationships. Int. J. Climatol., 20(6), 641-661. https://doi.org/10.1002/(SICI)10 97-0088(200005)20:6<641::AID-JOC501>3.0.CO;2-1

Wilby, R.L., Dawson, C.W., and Barrow, E.M. (2002). SDSM-a decision support tool for the assessment of regional climate change impacts. Environ. Model. Software, 17(2), 145-157. https://doi. org/10.1016/S1364-8152(01)00060-3

Willmott, C.J., Rowe, C.M., and Philpot, W.D. (1985). Small-scale climate maps: A sensitivity analysis of some common assumptions associated with grid-point interpolation and contouring. The American Cartographer, 12(1), 5-16.

Xia, X.H., Wu, Q., Mou, X.L., and Lai, Y.J. (2015). Potential impacts of climate change on the water quality of different water bodies. J. Environ. Inf., 25(2), 85-98. https://doi.org/10.3808/jei.201400263

Yatagai, A., Kamiguchi, K., Arakawa, O., Hamada, A., Yasutomi, N., and Kitoh, A. (2012). APHRODITE: Constructing a long-term daily gridded precipitation dataset for Asia based on a dense network of rain gauges. Bull. Am. Meteorol. Soc., 93(9), 1401-1415. https://doi.org/10.1175/BAMS-D-11-00122.1 